\title{
Total thyroidectomy can still remain the method of choice in some Bethesda III cases
}

\author{
Jindrich Lukas ${ }^{1,2}$, Barbora Hintnausova ${ }^{3}$, Vlasta Sykorova ${ }^{4}$, Martin Syrucek $^{5}$, Marek Maly ${ }^{6}$, Jaroslava Duskova ${ }^{7}$
}

\begin{abstract}
Background. The latest WHO classification of tumours of endocrine organs defines new units of borderline thyroid tumours (BTT). The aim of our study was to evaluate ultrasonographic and cytological features, mutation profile and surgery treatment in rare thyroid tumours.

Methods. An analysis of 8 BTT out of 487 patients, who underwent thyroid surgery between June 2016 and June 2020. The definitive diagnosis was made postoperatively by extensive histopathological examination. Molecular genetic analysis of genes associated with thyroid oncology (BRAF, HRAS, KRAS, NRAS, TERT, TP53, fused genes) were performed from one $F N A B$, and 7 formalin-fixed paraffin-embedded (FFPE) samples.

Results. BTT were found in a total of 8 patients (1.6\%), with a predominance of men with respect to other operated patients. FNAB samples were classified in the Bethesda system as Bethesda I, Bethesda II and Bethesda III in one, four and three cases, respectively. Hemithyroidectomy and total thyroidectomy were performed equally in four patients. The histopathological diagnosis revealed non-invasive encapsulated follicular neoplasm with papillary-like nuclear features (NIFTP) in three patients, follicular tumour of uncertain malignant potential (FT-UMP) in three patients, well differentiated tumour of uncertain malignant potential (WDT-UMP) in one patient, and hyalinizing trabecular tumour (HTT) in one case. In NIFTP cases mutation in HRAS gene in one patient together with probable pathogenic variant in TP53 gene and in NRAS gene in two patients were detected. In HTT patient PAX8/GLIS3 fusion gene was detected.

Conclusion. The surgical treatment of BTT is necessarily individual influenced by preoperative clinical, ultrasonographic, cytological and molecular genetic findings, and the presence of other comorbidities.
\end{abstract}

Key words: borderline thyroid tumour, FNAB, molecular testing of thyroid, thyroidectomy

Received: June 10, 2021; Revised: June 10, 2021; Accepted: June 30, 2021; Available online: July 20, 2021

https://doi.org/10.5507/bp.2021.045

(c) 2023 The Authors; https://creativecommons.org/licenses/by/4.0/

'Department of Otolaryngology-Head and Neck Surgery, Na Homolce Hospital, Prague, Czech Republic

2Ear, Nose, and Throat Department, Faculty of Medicine in Pilsen, Charles University in Prague, Czech Republic

${ }^{3}$ Department of Endocrinology, Na Homolce Hospital, Prague, Czech Republic

${ }^{4}$ Institute of Endocrinology, Department of Molecular Endocrinology, Prague, Czech Republic

${ }^{5}$ Department of Pathology, Na Homolce Hospital, Prague, Czech Republic

${ }^{6}$ Department of Biostatistics, National Institut of Public Health, Prague, Czech Republic

${ }^{7}$ Institute of Pathology, $1^{\text {st }}$ Faculty of Medicine, Charles University, Prague, Czech Republic

Corresponding author: Jaroslava Duskova, e-mail: jaroslava.duskova@lf1.cuni.cz

\section{INTRODUCTION}

The 4th edition of the WHO classification of tumours of the endocrine organs 2017, defined new units of borderline thyroid tumours (BTT) filling a grey area in pathological diagnosis between benign and malignant follicular cell derived tumours. These encompass units of encapsulated or well-circumscribed tumours with uncertain invasion of tumour cells into the tumour capsule or vessels with missing or questionable nuclear features of papillary thyroid carcinoma -follicular tumour of uncertain malignant potential (FT-UMP) and well differentiated tumours of uncertain malignant potential (WDT-UMP), respectively ${ }^{1}$. Papillary thyroid carcinoma (PTC) is the most frequent cancer of the thyroid gland and is divided into several histological variants with the follicular variant (FV PTC) as one of the most common. A subset of encapsulated FV PTC (EFVPTC) without evidence of capsular and/or lymphovascular invasion were reclassified as non-invasive follicular thyroid neoplasm with papillary-like nuclear features (NIFTP) by the Nikiforov group in 2016 (ref. ${ }^{2}$ ).

NIFTP can be suggested as a differential diagnostic option in FNAB ( ref. $^{3-5}$ ) nevertheless, it is definitively diagnosed, similar to other follicular tumours following extensive histopathological examination. The diagnostic criteria of NIFTP include encapsulation or partial encapsulation with clear demarcation, follicular pattern, no psammoma bodies, absence of invasion, necrosis or higher mitotic activity and less than $30 \%$ of the tumour volume showing a trabecular, insular or solid architecture. The nuclear features of papillary carcinoma must be expressed by the WHO newly standardized score of 2 or 3 (ref. ${ }^{1}$ ). The original criteria allowed $<1 \%$ papillae ${ }^{1}$, but current criteria do not allow any well-formed papillary structures. Finding of the BRAFV600E mutation or other mutations (e.g. $R E T / P T C$ ) or high-risk mutations (e.g. TERT promoter, TP53) precludes a diagnosis of NIFTP $\left(\right.$ ref. $\left.^{6}\right)$. 
About $20-30 \%$ of samples ${ }^{7,8}$ obtained by fine-needle aspiration biopsy are classified as uncertain/suspected category III-V in the BSRTC (Bethesda System for Reporting Thyroid Cytopathology) classification. In preoperative diagnosis, the determination of genetic markers may be beneficial. With their help, these tumours can be better stratified in terms of aggression and risk of disease recurrence and overtreatment in low-risk tumours can be avoided. Mutation of the RAS gene is considered to be the dominant genetic finding especially in NIFTP. Other mutations e.g. $P A X 8 / P A R G$ rearrangement, THADA (thyroid adenoma-associated) fusions, $E I F 1 A X$ and occasionally $B R A F$ K601 mutation can be helpful to suggest NIFTP preoperatively 9 .

Hyalinizing trabecular tumour (HTT) is a rare encapsulated or well-circumscribed tumour consisting of solid-alveolar to trabecular arrangement of cells, with elongated to round nuclei, noticeable nuclear grooves and intranuclear pseudoinclusions, intertrabecular and pericellular hyaline material. HTT tumour cells show positive expression of TTF-1, thyroglobulin and characteristic membrane positivity of Ki-67 (ref. ${ }^{1,10}$ ). A key finding in preoperative diagnosis is the detection of the PAX8/GLIS 3 fusion gene ${ }^{11,12}$ that is considered to be specific for this type of tumour. Data on long-term follow-up of these lesions are limited, however, the incidence of recurrences and metastasis is quite rare in less than $0.2 \%$ of cases ${ }^{7}$. Follicular adenoma, adenomatous node, FV PTC, follicular thyroid carcinoma (FTC), and medullary carcinoma (MTC) must be ruled out in the differential postoperative diagnosis ${ }^{13,14}$. HTT and NIFTP are mostly tumours with indolent behaviour. A conservative approach to surgical treatment (lobectomy) is an effective procedure in these tumours, unless TSH suppression and iodine radiotherapy are required in patients ${ }^{13,15}$.

The aim of this study was to evaluate preoperative ultrasonographic and cytological features and molecular genetic results and, to comment on the extent and results of operations in individuals with the rare BTT of the thyroid gland. As an illustration, we present a case report of a patient with HTT.

\section{MATERIALS AND METHODS}

An analysis of 487 operated patients, 8 of whom had a histopathologically proven rare tumour of uncertain biological behaviour - BTT. They were operated in the range of HTE/TTE by one surgeon (JL) at the Department of ENT and Head and Neck Surgery at Na Homolce Hospital (NNH), in the period 6/2016-6/2020. The postoperative follow-up period was $6-65$ months. The operations were performed on the basis of clinical, ultrasonographic (USG) and FNAB findings under USG control. Cytological samples were classified according to BSRTC (2017). Postoperative histopathological diagnosis was determined by two experienced pathologists at the Department of Pathology NNH (MS) and the Institute of Pathology $1^{\text {st }}$ Faculty of Medicine and Faculty General Hospital, Prague (JD). Molecular genetic testing of one FNAB and 7 formalin-fixed paraffin-embedded (FFPE) was performed in the Department of Molecular Endocrinology of the Institute of Endocrinology in Prague (VS).

\section{DNA and RNA extraction}

AllPrep DNA/RNA/miRNA Universal Kit (Qiagen) was used for extraction of DNA and RNA from FNAB and AllPrepDNA/RNA FFPE Kit (Qiagen) for extraction of DNA and RNA from FFPE according to the manufacturer's instructions. DNA and RNA concentrations were measured using a fluorometer (Qubit 2.0, Invitrogen).

\section{Detection of point mutations in FNAB}

According to our diagnostic procedure, firstly, FNA samples were analysed for $B R A F$ V600E mutation using allele-specific Real Time PCR using BRAF Mutation Analysis Kit II (EntroGen). If no $B R A F$ V600E mutation was found, the analysis continued by next generation sequencing using Thyro-ID kit (4bases) based on targeted amplification of 14 genes including HRAS (exon 2, 3, NM_005343.4), KRAS (exon 2, 3, NM 033360.4), NRAS (exon 2, 3, NM_002524.5), BRAF (exon 15, NM_004333.6) and TERT (promoter, NM_198253.3) genes and sequencing on Miseq (Illumina). Bioinformatic data evaluation was performed using VarSome Clinical (Saphetor SA).

\section{Detection of $B R A F, H R A S, K R A S$ and NRAS mutations in FFPE samples}

The detection of point mutations in BRAF (exon 15, NM_004333.6), HRAS (exons 2, 3, NM_005343.4), $K R A S$ (exons 2, 3, NM_033360.4), NRAS (exons 2, 3, NM_002524.5) and TP53 (exon 6, NM_000546.5) genes was performed in all samples as described previously $^{16}$. DNA was amplified using gene-specific primers that are available with PCR conditions on request. The PCR products were purified using Agencourt AMPure (Beckman Coulter), libraries were prepared using a Nextera XT DNA Library Prep Kit (Illumina) according to the manufacturer's protocol and sequenced for 500 cycles by MiSeq Reagent Kit V2 (Illumina) using a MiSeq sequencer (Illumina). Integrative Genomics Viewer was used for sequence data visualization.

\section{Detection of TERT mutations in FFPE samples}

The detection of point mutations in TERT (promoter, NM_198253.3) gene was performed in all samples as described previously ${ }^{16}$. The PCR products of TERT promoter were purified using Agencourt AMPure (Beckman Coulter), and then sequencing reaction using Quick Start Master Mix Kit with Dye Terminator Cycle Sequencing (Beckman Coulter) was performed Products of the sequencing reaction were purified using Agencourt Clean SEQ Dye-Terminator Removal (Beckman Coulter). Capillary sequencing was performed by CEQ 8000 instrument (Beckman Coulter). Analyses were evaluated by CEQ 8000 software (Beckman Coulter). The primer sequences and PCR conditions are available on request. 
Table 1. Overview of patients, procedures and examination results.

\begin{tabular}{|c|c|c|c|c|c|c|c|c|c|}
\hline Patient & $\begin{array}{l}\text { Sex } \\
(M / F)\end{array}$ & $\begin{array}{l}\text { Age } \\
\text { (years) }\end{array}$ & $\begin{array}{l}\text { USG sn/mn } \\
{[\mathrm{mm}]}\end{array}$ & TI-RADS & $\begin{array}{l}\text { FNAB Bethesda } \\
\text { classification }\end{array}$ & $\begin{array}{l}\text { Surgery } \\
\text { TTE/HTE }\end{array}$ & $\begin{array}{l}\text { Histo-patho- } \\
\text { logical dg. }\end{array}$ & $\begin{array}{l}\text { Molecular } \\
\text { analysis } \\
\text { (mutated gene) }\end{array}$ & $\begin{array}{l}\text { Follow-up } \\
\text { (months) }\end{array}$ \\
\hline 1 & $\mathrm{M}$ & 61 & $\begin{array}{r}\text { mn } 17 \times 15 \times 22 \\
19 \times 16 \times 19\end{array}$ & $4 \mathrm{~b}$ & III. AUS/FLUS & TTE & NIFTP & $N R A S$ & 18 \\
\hline 2 & M & 41 & sn $67 \times 48 \times 35$ & 2 & II. Benign & HTE & NIFTP & $\begin{array}{l}H R A S \\
\text { TP53 }\end{array}$ & 6 \\
\hline 3 & $\mathrm{~F}$ & 69 & sn $35 \times 30 \times 25$ & 3 & II. Benign & HTE & FT-UMP & 0 & 6 \\
\hline 4 & M & 66 & sn $30 \times 25 \times 14$ & $4 b$ & III. AUS/FLUS & TTE & FT-UMP & 0 & 26 \\
\hline 5 & M & 50 & sn $31 \times 25 \times 26$ & 5 & II. Benign & TTE & FT-UMP & 0 & 58 \\
\hline 6 & $\mathrm{~F}$ & 53 & sn $32 \times 30 \times 43$ & 2 & II. Benign & HTE & WDT-UMP & 0 & 60 \\
\hline 7 & M & 48 & sn $40 \times 30 \times 25$ & $4 \mathrm{c}$ & III. AUS/FLUS & TTE & HTT & PAX8/GLIS3 & 26 \\
\hline 8 & M & 38 & sn $40 \times 27 \times 27$ & 2 & I. Non-diagnostic & HTE & NIFTP & $N R A S$ & 14 \\
\hline
\end{tabular}

M, male; F, female; mn, multinodular nodosity; USG, ultrasonography; sn, solitary nodosity; HTE/TTE, hemithyroidectomy/total thyroidectomy; FNAB, Fine Needle Aspiration Biopsy; AUS, atypia of undetermined significance; FLUS, follicular lesion of undetermined significance; NIFTP, non-invasive follicular thyroid neoplasm with papillary-like nuclear features; HTT, hyalinizing trabecular tumour; FT-UMP, follicular tumour of uncertain malignant potential; WDT-UMP, well differentiated tumour of uncertain malignant potential; 0 , no somatic pathogenic variant in the tested genes (BRAF, HRAS, KRAS, NRAS, TERT, TP53) or the presence of the tested PAX8/PPARG fusion gene was detected in the examined material; TI-RADS categories: TI-RADS 2, very low suspicion; TI-RADS 3, low suspicion; TI-RADS 4a, middle suspicion; TI-RADS 4b,4c, 5, high suspicion.

Detection of PAX8/GLIS3 and PAX8/PPARG fusion gene

In samples without detected driver mutation, analysis of $P A X 8 / P P A R G$ fusion genes (the fusion of exon 8,9 or 10 of $P A X 8$ gene (NM_003466.3) with exon 2 of PPARG gene (NM005037.5) was performed. In HTT, the presence of the $P A X 8 / G L I S 3$ fusion was analysed (the fusion of exon 2 of the PAX8 gene (NM_003466.3) with exon 3 of the GLIS3 gene (NM_001042413.2). The analysis of the fusion genes was performed by Real-Time PCR. First, RNA was reverse transcribed into cDNA using random primers, AMV reverse transcriptase, RNase inhibitor, and dNTPs reagents. Subsequently, the cDNA was amplified using Sso Advanced Universal SYBR Green Supermix (Bio-Rad) and gene-specific primers. The primer sequences and PCR conditions are available on request. Real-Time PCR was performed using a Light Cycler 480 (Roche) and data were evaluated using a Light Cycler 480SW1.5.1. (Roche).

\section{Statistical analysis}

Categorical data are presented as counts and percentages, continuous data are described by means and SD. Between-group comparisons were carried out using Fisher's exact test and two-sample t-tests for categorical and continuous data respectively. $P$-values less than 0.05 were considered statistically significant.

\section{RESULTS}

Demographic data, preoperative clinical and cytological findings, extent of surgery, postoperative histopathological and molecular genetic results are shown in Table 1.

A total of 487 patients were operated on during the study period. Benign thyroid diseases were found in 388 patients $(79.7 \%)$, and thyroid carcinomas occurred in 91 (18.7\%) patients.

BTT were found in a total of 8 operated patients (1.6\%). This cohort of patients was characterized by a predominance of men ( 6 men, 2 women).

The mean age of patients with BTT was 54.36 years (range 38-69 years), in other patients it was 53.7 years (range 19-83 years), the difference was not statistically significant $(P=0.919)$. Preoperative FNAB was performed in a total of 193 patients $(39.6 \%)$ and classification into individual BSRTC categories was: a non-diagnostic/unsatisfactory sample (Bethesda I, 3.9\%); a benign (Bethesda II, 20.3\%); atypia/follicular lesions of undetermined significance (Bethesda III -AUS / FLUS, 6.6\%); follicular neoplasm/suspicious for a follicular neoplasm (Bethesda IV - FN/SFN, 4.5\%), suspicious for malignancy (Bethesda V - SM, 3.3\%) and malignant (Bethesda VI, 1\%).

In the BTT group, there was once $(12.5 \%)$ a nondiagnostic/insufficient sample (BI-ND/UNS), a benign finding (BII) in four cases (50\%), and atypia/follicular lesions of undetermined significance (BIII-AUS/FLUS) in three patients $(37.5 \%)$. Other categories BIV-VI of the BSRTC did not appear in this group.

Total thyroidectomy (TTE) was performed in 3 patients with the cytological classification BIII-AUS/ FLUS and in a patient with the cytological classification Bethesda II, who underwent external radiotherapy of the neck for Hodgkin's lymphoma with involvement of the cervical lymph nodes before the operation.

Hemithyroidectomy (HTE) was performed in three patients with the Bethesda II category and in patients with a non-diagnostic cytological specimen. All procedures were without postoperative complications. THE was performed in $50.0 \%$ of patients. 


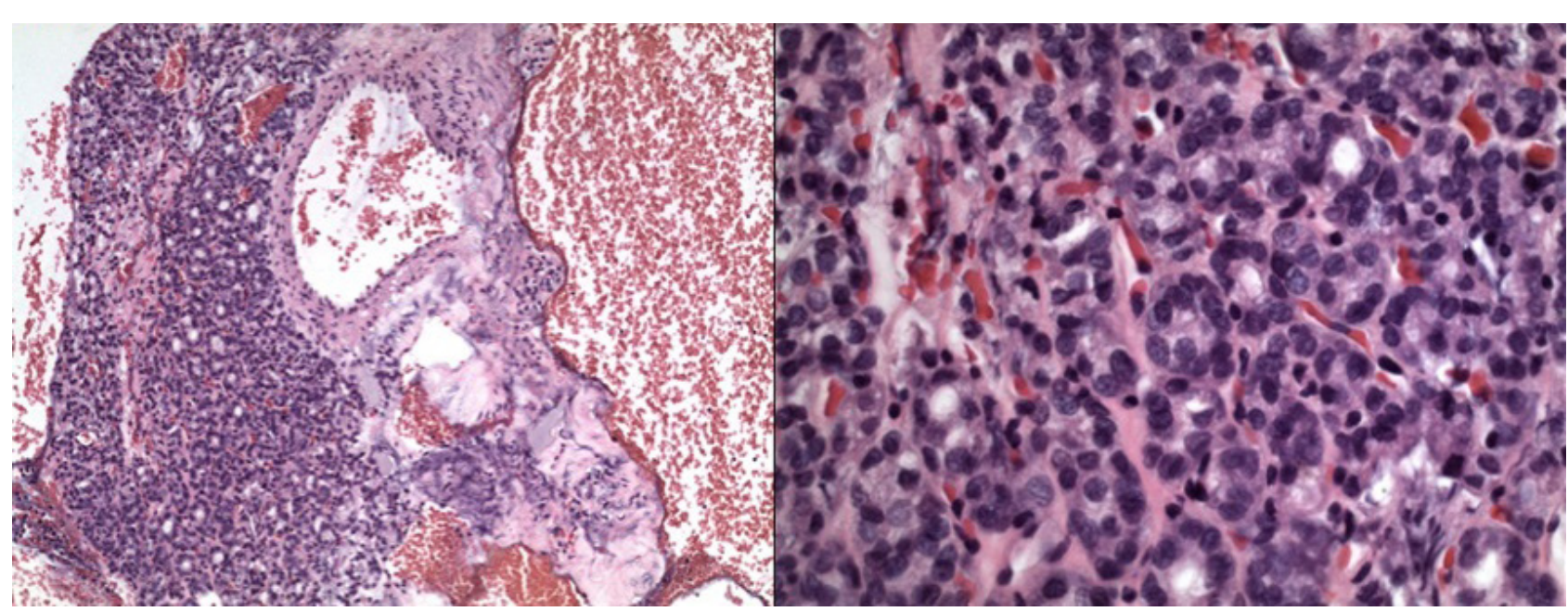

Fig. 1 A, B. FNAB cytoblock of the HTT case: Microphragment of a microfollicular homogeneous nodule with calcifications and FVPTC - like nuclei. Obj. magnif. 10× and 40×.

\section{Molecular genetic testing}

In three NIFTP patients pathogenic variants in $R A S$ genes - c.182A>G p. (Gln61Arg) in exon 3 of $N R A S$ gene in two cases and c.181C>A p. (Gln61Lys) in exon 3 of HRAS gene were detected. In NIFTP patient with HRAS mutation, a probable pathogenic variant c. $586 \mathrm{C}>\mathrm{T}$ (p.Arg196Ter) in exon 6 of TP53 gene was detected. In a patient with HTT, a PAX8/GLIS3 fusion gene was detected from the surgically removed tissue. In the remaining four cases (1 WDT-UMP and 3 FT-UMP), no somatic pathogenic variant in the analysed $B R A F, H R A S, K R A S$, NRAS, TERT, TP53 genes associated with thyroid oncology, nor the presence of the PAX8/PPAR $\gamma$ fusion gene was detected (see Table 1).

\section{Illustration case report}

A male, 48-years old, euthyroid, observed a solitary node in the thyroid gland for about 4 months. Ultrasound examination revealed a right lobe $22 \times 17 \times 42 \mathrm{~mm}$ and a left lobe $19 \times 16 \times 47 \mathrm{~mm}$. A voluminous hypoechogenic nodule $27 \times 25 \times 30 \mathrm{~mm}$ with numerous minor calcifications and increased vascularization was found in the isthmic part and right lower lobe reaching the upper edge of the sternum. According to ATA, high node suspicion, classification TI-RADS $4 \mathrm{c}\left(\right.$ ref. $^{17}$ ). Fine needle aspiration biopsy from a nodule under ultrasonography control was performed. Cytological evaluation revealed a microphragment of microfollicular tumour with calcifications and nuclei bearing some features of FVPTC - overlapping non-round nuclei with grooves and pseudoinclusions in Fig. 1. The cytopathology finding was classified as Bethesda III - AUS (atypia of undetermined significance) in the Bethesda system 2017 (ref. ${ }^{18,19}$ ). CT examination confirmed an enlarged isthmus of 21-26 mm and an inhomogeneous nodule of $28 \times 25 \times 29 \mathrm{~mm}$ with calcifications in Fig. 2 . Histopathological verification was recommended. Total thyroidectomy was performed without postoperative complications. Histopathology investigation found a welldefined nodule with solid alveolar and trabecular arrangement. The cells had voluminous eosinophilic cytoplasm

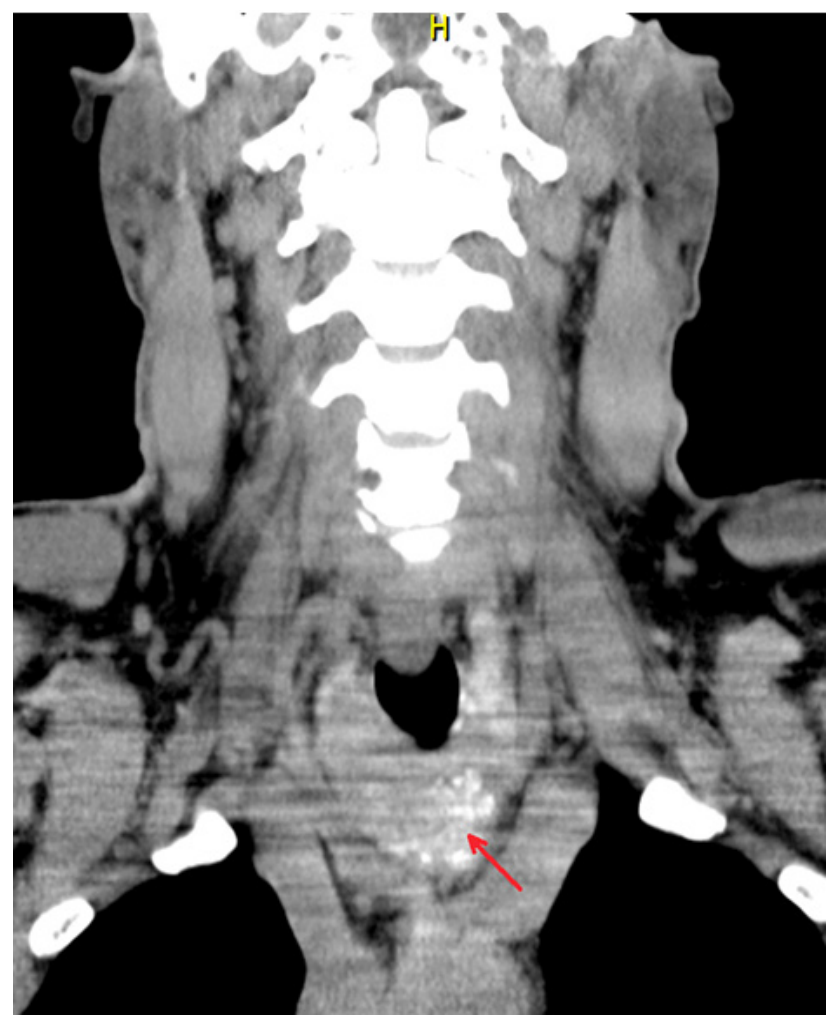

Fig. 2. CT scan: Enlarged isthmus of the thyroid gland 21-26 $\mathrm{mm}$, which reaches the edge of the sternum with inhomogeneous nodule $25 \times 25 \times 29 \mathrm{~mm}$ and calcifications.

of oncocytic appearance. There were numerous calcifications and an abundant vascularization in the tumour. Cell nuclei were irregular with intranuclear pseudoinclusions and grooves. Immunohistochemistry revealed positive chromogranin, TTF1, CD 56, CD 31 positive in blood vessels, synaptophysin, $\mathrm{Ki} 67$ in $1 \%$ and S100 negative. Angioinvasion was not shown and amyloid staining was negative. In the primary evaluation, medullary carcinoma was suspected and a consultation examination with an extension of the immunohistochemical panel was requested. 


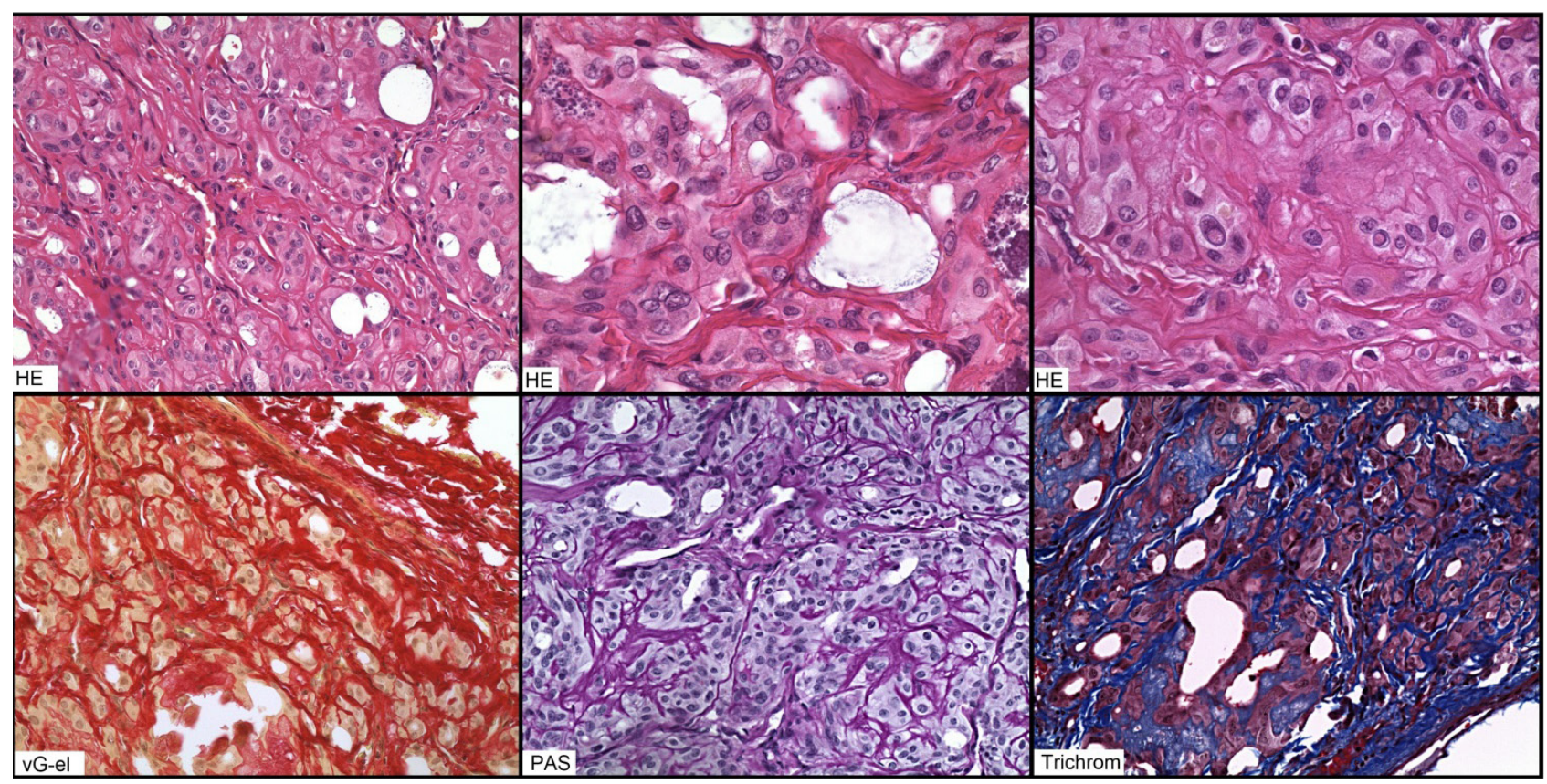

Fig. 3. Histopathology of the resecate. Solid trabeculer and microfollicular arrangement with inter- and intratrabecular fibrosis. Nuclei with the features of PTC nuclei. HE, vG - el, trichrome, PAS staining. Obj. magnif. 20× and 40×.

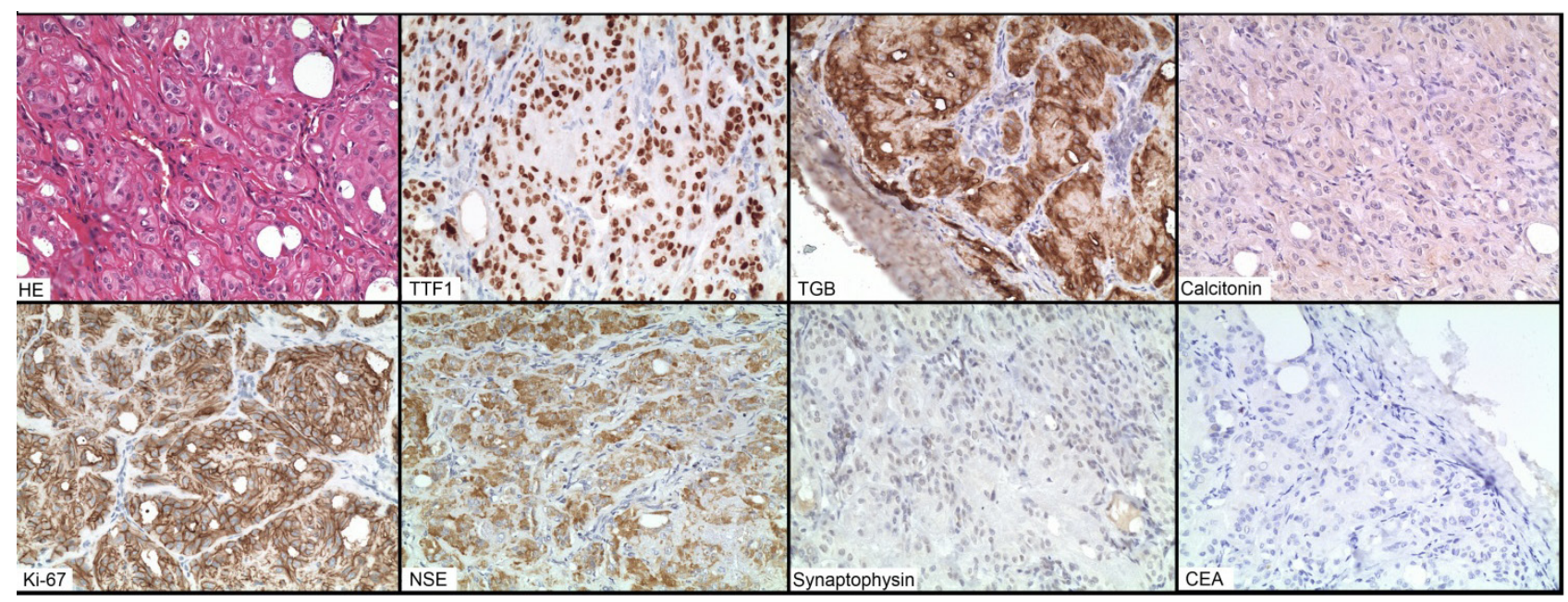

Fig. 4. Immunohistochemistry. TTF1, TGB, NSE - positive. Calcitonin, synaptophysin, CEA - negative. Ki-67 (MIB1) with typital for HTT menbranout positivity. Obj. magnif. 20×.

Additional immunohistochemical examination was performed. Calcitonin and CEA were negative; thyroglobulin and TTF1 were diffusely positive, NSE had disperse positivity. Ki-67 (MIB1) exhibited membrane positivity of neoplastic cells. In relation to the morphological features (inter-and intratrabecular fibrosis, papillary carcinoma -like nuclei) and immunohistochemical profile (TTF1+, calcitonin-, Ki-67 (MIB1) - membrane positivity) second reading determined the final diagnosis of hyalinizing trabecular tumour in Fig. 3,4.

Molecular analysis of fusion genes from FFPE by RealTime PCR (iQ SYBR Green Supermix, BIO-RAD, Light Cycler 480, Roche) detected a PAX8/GLIS3 fusion gene (fusion of exon 2 of $P A X 8$ gene with exon 3 of GLIS3 gene).

\section{DISCUSSION}

Individual variants of newly classified BTT differ in clinical behaviour, prognosis and molecular profile ${ }^{2,15}$ and may lead to a false positive diagnosis of papillary or medullary carcinoma ${ }^{15,19}$.

In recent years, laboratories worldwide have made enormous effort to search for molecular markers that could preoperatively distinguish benign from malignant thyroid nodules ${ }^{20}$. There are two main approaches, ruleout and rule-in analysis, or a combination of both. The aim of the rule-out approach is to identify benign nodules based on expression analysis of microRNA or DNA methylation profiling and to avoid unnecessary surgery. On the other hand, rule-in approach efforts to identify malignant nodules by detecting mutations specific for malignancy, leading to recommendation of the extent of surgery ${ }^{21}$. 
Several molecular markers were identified. The most common genetic change of thyroid carcinomas is V600E mutation in the BRAF gene that is associated with $100 \%$ risk of malignancy. This mutation is specific for papillary thyroid carcinoma (PTC) and poorly differentiated thyroid carcinoma (PDTC) or anaplastic thyroid carcinoma (ATC) dedifferentiated from PTC (ref. ${ }^{21}$ ). Mutations in the promoter of the TERT gene occurring in all types of thyroid malignant tumours are associated with almost $100 \%$ risk of malignancy as well as presence of $R E T$, NTRK, ALK or BRAF fusion genes ${ }^{22}$.

In postoperative histopathological diagnosis, immunohistochemically detectable markers - thyroid transcription factor -1 (TTF-1) contribute to confirm the origin of thyroid or to detect malignancy e.g. calcitonin in suspected medullary carcinoma, to a certain extent galectin 3 , mesothelial 1 (Hector Battifora Mesothelial cell, cytokeratin -19 .

Other markers are also proposed, e. g. CITED1, S100A, fibronectin-1, but so far without further detailed information $^{23}$. In our cohort, $R A S$ mutations were detected in all three cases of NIFTP. NRAS and HRAS mutations are somatic pathogenic variants detected in exons 2 or 3. RAS mutations have been detected in all types of thyroid tumours, both benign and malignant, well differentiated or undifferentiated, thus their clinical significance is still unclear ${ }^{24}$. The risk of malignancy in FNAB with $R A S$ mutation is reported between $57-87 \%$ of cases ${ }^{15}$. In borderline follicular tumours, somatic $R A S$ mutations have a high prevalence (in $30-67 \%$ of cases) (ref. ${ }^{15}$ ).

Patel et al. hypothesize that pathogenic variants in $R A S$ genes are early transformation in benign tumours and may be predisposed to progression to cancer ${ }^{24}$.

In a NIFTP patient with $H R A S$ mutation additional variant in TP53 gene was detected. In databases the variant is considered to be pathogenic and it was confirmed in functional studies ${ }^{22}$. Their clinical significance in NIFTP is unclear, however in general, pathogenic variants in TP53 gene are associated with more aggressive tumour behaviour. In revised diagnostic criteria for NIFTP, absence of TP53 mutations is recommended but not required for NIFTP diagnosis and the presence of such high-risk mutations should trigger an exhaustive search for invasive features and papillary formations and more careful followup of patients ${ }^{6}$.

In four cases, we did not detect any of the analysed somatic pathogenic variants of the tested genes. Similar results are reported by other authors ${ }^{21,25}$.

In most cases, these are low-risk tumours with a favourable prognosis. The risk of recurrence or metastasis is very low but data on the long-term outcome of these tumours are limited. Completely removed lesions pose a risk of recurrence less than $1 \%$ and thus less radical surgery as lobectomy is recommended ${ }^{21}$. During the fiveyear follow-up period, our monitored patient developed no lymph node or distant metastases.

French et al. ${ }^{26}$ consider capsule thickness as a predictive marker of invasion. The thickness of the tumour capsule is significantly thinner in NIFTP compared to non-invasive encapsulated FVPTC, where it is thicker than $0.2 \mathrm{~mm}$ and which increases the suspicion of malignancy. The size of the tumour does not constitute a criterion for the diagnosis of NIFTP (ref. ${ }^{6,27}$ ).

HTT is macroscopically a well-circumscribed or encapsulated nodule, white coloured, mostly asymptomatic. HTT tumour cells show positive expression of TTF-1, thyroglobulin, characteristic membrane positivity of Ki-67 (MIB1), with negative expression of calcitonin ${ }^{10}$. Ki-67 clone MIB1 helps to confirm HTT only with this clone and under defined conditions ${ }^{28}$.

The aetiology of the tumour is not entirely elucidated. The cytological characteristics are similar to papillary carcinoma. It is considered by some authors to be a morphological variant of PTC, with overlapping nuclear changes, chromatin clarification and a high prevalence of RET/PTC rearrangement ${ }^{29,30}$. Activation of the RET/PTC gene and production of the RET protein are involved in the nuclear changes that are typical of PTC. Some studies reported presence of $R E T / P T C$ rearrangement also in other tumours and lesions, such as lymphocytic thyroiditis $^{31}$. However subsequent studies did not confirm the presence of RET/PTC rearrangement in HTT or other lesions except of PTC. According to the literature, only $8 \%$ of preoperative diagnoses of HTT are determined on the basis of cytological analysis ${ }^{30,32}$. This possibility should be considered in the differential diagnosis more frequently ${ }^{32,33}$. The absence of the $B R A F$ mutation in HTT questions its association with PTC (ref. ${ }^{34,35}$ ). The presence of hyaline material in HTT can be mistaken for amyloid and lead to a differential diagnostic consideration of medullary carcinoma ${ }^{10,30}$. The situation was similar in our case of a patient with HTT (see the case report). In a recent study based on sequence analysis and other techniques, Nikiforova et al. detected a new PAX8/GLIS3 fusion gene that is believed to be specific for HTT and could become key in the preoperative diagnosis of $\mathrm{HTT}^{10,29}$. Nikiforova et al. consider the finding of the PAX8/GLIS3 fusion gene as a specific marker for the diagnosis of HTT (ref. ${ }^{11}$ ).

\section{CONCLUSION}

BTT are lesions with borderline histological findings between benign and malignant thyroid tumours and in most cases with indolent clinical behaviour. During the five-year follow-up period, no monitored patient developed lymph node or distant metastases. However, even with this favourable profile, surgical treatment is necessarily individual. It is influenced by preoperative clinical, ultrasonographic, cytological and molecular genetic findings, as well as the presence of other comorbidities. The definitive diagnosis is made on the basis of postoperative histopathological examination. Molecular genetic analysis contributes to the diagnosis of these lesions, and detection of the PAX8/GLIS3 fusion gene is considered a specific finding in HTT. 


\section{ABBREVIATIONS}

FNAB, Fine Needle Aspiration Biopsy; WHO, World Health Organization; TSH, Thyroid stimulating hormone; EFVPTC, Encapsulated Follicular Variant of Papillary Thyroid Carcinoma; TI-RADS, Thyroid Imaging Reporting and Data System; BSRTC, Bethesda System for Reporting Thyroid Cytopathology; ATA, American Thyroid Association.

Acknowledgements: This work was supported by Internal Grant from the Ministry of Health of the Czech Republic, Na Homolce Hospital - NNH, 00023884, IG192301 and was approved by the Ethical Committee of the NNH. Supported by Charles University - Progres Q28/LF1 project Supported by the Ministry of Health of the Czech Republic - RVO project VFN64165 and by MH CZ DRO (Institute of Endocrinology - EÚ, 00023761).

Author contributions: JL: surgeon and conceptualization, manuscript writing; JD: conceptualization, final approval and supervition; VS: data analysis, following -up, final approval; BH: data analysis; MS: histological verification; MM: statistician.

Conflicts of interest statement: The authors have no conflict of interest to declare.

\section{REFERENCES}

1. Lloyd RV, Osamura RY, Klöppel G, Rosai J. WHO classification of tumours of endocrine organs (4th ed.). Lyon: IARC; 2017:355.

2. Nikiforov YE, Seethala RR, Tallini G. Baloch WB, Basolo F, Thompson LDR, Barletta JA, Wenig BM , Al Ghuzlan A, Kakudo K, Giordano TJ Alves VA, Khanafshar E, Asa SL, El-Naggar AK, Gooding WE, Hodak SP, Lloyd RV, Maytal G, Mete O, Nikiforova MN, Nosé V, Papotti M, Poller DN, Sadow PM, Tischler AS, R Michael Tuttle RM, Wall KB, LiVolsi VA, Randolph GW, Ghossein RA. Nomenclature revision for encapsulated follicular variant of papillary thyroid carcinoma: A paradigm shift to reduce overtreatment of indolent tumors. JAMA Oncol 2016;2(8):1023-29.

3. Yang GCH, Fried KO, Scognamiglio T. Sonographic and cytologic differences of NIFTP from infiltrative or invasive encapsulated follicular variant of papillary thyroid carcinoma: A review of 179 cases. Diagn Cytopathol 2017;45(6):533-41.

4. Yan L, Sethi S, Park JW. Cytologic and clinical features of NIFTP: Can we diagnose based on preoperative fine-needle aspiration. Diagn Cytopathol 2019;47(12):1259-66.

5. Zhang Z, Chhieng D, Harshan M, Zheng X, Zakowski M. Cytological features of noninvasive follicular thyroid neoplasm with papillarylike nuclear features (NIFTP). J Am Soc Cytopathol 2019;8(1):5-10.

6. Nikiforov YE, Baloch ZW, Hodak SP, Giordano TJ, Lloyd RV, Seethala $\mathrm{RR}$, Wenig BM. Change in diagnostic criteria for noninvasive follicular thyroid neoplasm with papillarylike nuclear features. JAMA Oncol 2018;4(8):1125-26.

7. Kakudo K, Bychkov A, Bai Y, Li Y, Liu Z, Jung ChKI. The new 4th edition World Health Organization classification for thyroid tumors, Asian perspectives. Pathol Int 2018;68(12):641-64.

8. Cibas ES, Ali SZ. The 2017 Bethesda system for reporting thyroid cytopathology. Thyroid 2017;27(11):1341-46.

9. Pusztaszeri M, Bongiovanni M. The impact of non-invasive follicular thyroid neoplasm with papillary-like nuclear features (NIFTP) on the diagnosis of thyroid nodules. Gland Surg 2019;8(S2):S86-S97.

10. Pokorová S, Zambo I. Hyalinizing trabecular tumor of the thyroid gland with transcapsular invasion: A case report. Cesk Patol 2018;63(4):191-94.

11. Nikiforova MN, Nikitski AV, Panebianco F, Kaya C, Yip L, Williams M Chiosea SI, Seethala RR, Roy S, Condello V, Santana-Santos L, Wald
Al, Carty SE, Ferris RL, El-Naggar AK, Nikiforov YE. GLIS rearrangement is a genomic hallmark of hyalinizing trabecular tumor of the thyroid gland. Thyroid 2019;29(2):161-73.

12. Marchio C, Da Cruz Paula A, Gularte-Merida R, Basili T, Brandes A, da Silva EM ,Silveira C, Ferrando L, Metovic J, Maletta F, Pareja F, Rubin BP,Hoschar AP, De Rosa G, La Rosa S, Bongiovanni M, Purgina B, Piana S, Volante M, Weigelt B, Reis-Filho JS, Papotti M. PAX8-GLIS3 gene fusion is a pathognomonic genetic alteration of hyalinizing trabecular tumors of the thyroid. Mod Pathol 2019;32(12):1734-43.

13. Rosario PW, Penna GC, Calsolari MR. Noninvasive encapsulated follicular variant of papillary thyroid carcinoma: Is lobectomy sufficient for tumours $1 \mathrm{~cm}$ ? Clin Endocrinol (Oxf). 2014;81(4):630-32.

14. Alves VAF, Kakudo K, LiVolsi V, Lloyd RV, Nikiforov YE, Nosé V, Papotti $M$, Thompson LDR. Noninvasive follicular thyroid neoplasm with papillary-like nuclear features (NIFTP): Achieving better agreement by refining diagnostic criteria. Clinics (Sao Paulo). 2018;73:e576.

15. Zajkowska K, Kopczynski J, Gozdz S, Kowalska A. Noninvasive follicular thyroid neoplasm with papillary-like nuclear features: A problematic entity. Endocr Connect 2020;9(3):R47-R48.

16. Pekova B, Dvorakova S, Sykorova V, Vacinova G, Vaclavikova $E_{\text {, }}$ Moravcova J, Katra R, Vlcek P, Sykorova P, Kodetova D, Vcelak J, Bendlova B. Somatic genetic alterations in a large cohort of pediatric thyroid nodules. Endocr Connect 2019;8(6):796-805. doi:10.1530/ EC-19-0069

17. Haugen BR, Alexander EK, Bible KC, Doherty GM, Mandel S, Nikiforov YE, Pacini F, Randolph GW, Sawka AM, Schlumberger M, Schuff KG, Sherman SI, Sosa JA, Steward DL, Tuttle RM, Wartofsky L. 2015 American Thyroid Association Management Guidelines for Adult Thyroid Nodules and Differentiated Thyroid Cancer. The American Thyroid Association Guidelines Task Force on Thyroid Nodules and Differentiated Thyroid Cancer. Thyroid 2016;26(1):1-133. doi: 10.1089/thy.2015.0020

18. Ali SZ, Cibas ES. The Bethesda system for reporting thyroid cytopathology: Definitions, criteria, and explanatory notes (1 st ed.). New York: Springer; 2010.

19. Duskova J. Current issues in fine needle aspiration biopsy of thyroid gland. Cesk Patol 2019;55(1):13-23. (In Czech)

20. Čáp J. Patologická diagnostika onemocnění štítné žlázy. [Pathology diagnostics of thyroid diseases] Medical Tribune 14/2016. Available from: https://www.tribune.cz/clanek/39876 (In Czech)

21. Paschke R, Cantara S, Crescenzi A, Jarzab B, Musholt TJ, Sobrinho Simoes M. European Thyroid Association guidelines regarding thyroid nodule molecular fine-needle aspiration cytology diagnostics. Eur Thyroid J 2017;6(3):115-29.

22. Shirole $N H$, Pal D, Kastenhuber $E$, Senturk S, Boroda J, Pisterzi $P$ Miller M, Munoz G, Anderluh M, Ladanyi M, Lowe SW, Sordella R. TP53 exon- 6 truncating mutations produce separation of function isoforms with pro-tumorigenic functions. Elife 2016;5:e17929. doi: 10.7554/eLife. 17929

23. Paunovic I, Isic T, Havelka M, Tatic S, Cvejic D, Savin S. Combined immunohistochemistry for thyroid peroxidase, galectin-3, ck19 and HBME- 1 in differential diagnosis of thyroid tumors. APMIS 2012;120(5):368-79.

24. Patel SG, Carty SE, McCoy KL, Ohori NP, LeBeau SO, Seethala RR, Nikiforova MN , Nikiforov YE, Yip L. Preoperative detection of RAS mutation may guide extent of thyroidectomy. Surgery 2017;161(1):168-75.

25. Xing $M$, Haugen BR, Schlumberger $M$. Progress in molecularbased management of differentiated thyroid cancer. Lancet 2013;381(9871):1058-69.

26. French B, Hattier G, Mardekian SK. Utility of tumor capsule thickness as a predictor of invasion in encapsulated follicular variant of papillary thyroid carcinoma and a diagnostic tool for noninvasive follicular thyroid neoplasm with papillary-like nuclear features. Int J Surg Pathol 2020;28(1):13-19.

27. Thompson LD. Ninety-four cases of encapsulated follicular variant of papillary thyroid carcinoma: A name change to noninvasive follicular thyroid neoplasm with papillary-like nuclear features would help prevent overtreatment. Mod Pathol 2016;29(7):698-707.

28. Hirokawa M, Shimizu M, Manabe T, Kuroda M, Mizoguchi Y. Hyalinizing trabecular adenoma of the thyroid: Its unusual cytoplasmic immunopositivity for MIB1. Pathol Int 1995;45(5):399-401.

29. Cheung CC, Boerner SL, Macmillan CM, Ramyar L, Asa SL. Hyalinizing trabecular tumor of the thyroid: A variant of papillary carcinoma 
proved by molecular genetics. Am J Surg Pathol 2000;24(12):162226.

30. Rossi ED, Papotti M, Faquin W, Larocca LM, Pantanowitz L. The diagnosis of hyalinizing trabecular tumor: A difficult and controversial thyroid entity. Head Neck Pathol 2020;14(3):778-84.

31. Papotti M, Volante M, Giuliano A, Fassina A, Fusco A, Bussolati G, Santoro M, Chiappetta G. RET/PTC activation in hyalinizing trabecular tumors of the thyroid. Am J Surg Pathol 2000;24(12):161521.

32. Rhee YY, Jung HK, Kim SH, Kim SH. Hyalinizing trabecular tumor of the thyroid gland, a diagnostic challenge in fine-needle aspiration cytology: Case report. J Pathol Transl Med 2018;52(4):252-56.

33. You TK, Jang KY, Moon WS, Ja Chung M, Jae Kang M, Lee DG, Park HS. Fine-needle aspiration cytology of hyalinizing trabecular ad- enoma of the thyroid in a patient with Hashimoto's thyroiditis: A case report. Acta Cytol 2012;56(4):448-52.

34. Salvatore G, Chiappetta G, Nikiforov YE, Decaussin-Petrucci M, Fusco A, Carney JA, Santoro M. Molecular profile of hyalinizing trabecular tumours of the thyroid: High prevalence of RET/PTC rearrangements and absence of B-raf and N-ras point mutations. Eur J Cancer 2005;41(5):816-21.

35. Liu Y, Huang X, Hu Y, Wang F, Du T, He W, Chen L, Lang B, Pu Q, Chen $\mathrm{H}$. Hyalinizing trabecular tumor of the thyroid: A clinicopathological analysis of four cases and review of the literature. Int J Clin Exp Pathol 2017;10(7):7616-26. 